RAZOÁVEL DURAÇÃO DO PROCESSO: A EFETIVIDADE DO DIREITO FUNDAMENTAL À TUTELA JURISDICIONAL TEMPESTIVA E A POSSIBILIDADE FÁTICA

\author{
ADELINA MARIA GURAK \\ SILVANA MARIA PARFIENIUK
}




\title{
RAZOÁVEL DURAÇÃO DO PROCESSO: A EFETIVIDADE DO DIREITO FUNDAMENTAL À TUTELA JURISDICIO- NAL TEMPESTIVA E A POSSIBILIDADE FÁTICA
}

\author{
ADELINA MARIA GURAK ${ }^{1}$ \\ SILVANA MARIA PARFIENIUK ${ }^{2}$
}

\section{RESUMO}

0 presente artigo tem por finalidade a realização de um estudo sobre o direito fundamental ao razoável prazo de duração do processo e a possibilidade fática da célere entrega da prestação jurisdicional. Para tanto, serão analisadas as causas que concorrem para a morosidade da Justiça, alvo de severas críticas nos últimos anos. Serão abordadas, ainda, as modificações introduzidas pela Emenda Constitucional $45 / 2004$, a par dos reflexos que tal reforma vem surtindo na prática forense. Foi desenvolvido com base em pesquisa bibliográfica e observação cotidiana, situando-se o tema na área de Direito Constitucional.

\section{Palavras-chave:}

Poder Judiciário; Emenda; Reforma; Morosidade; Efetividade; Celeridade.

\section{ABSTRACT}

The current article aims to carry out a study about the fundamental right to the reasonable legal process deadline and the factual possibility of swift delivery of the jurisdictional render. Therefore, the cause which contributes to slowness of justice, which has received strict critics in the last few years, will be analyzed. Yet, the changes introduced by the Constitutional Amendment number 45/2004 will be tackled regarding the reflex that such reform has been causing in the

\footnotetext{
${ }^{1}$ Pós-graduanda em Direito Constitucional pela Universidade do Tocantins - UNITINS e Juiza de direito titular da $1^{\mathrm{a}}$ Vara da Fazenda de Registros Públicos de Palmas-TO

${ }^{2}$ Pós-graduanda em Direito Constitucional pela Universidade do Tocantins - UNITINS e Juiza de direito titular do Juizado Especial da Infância e Juventude de Palmas-TO
} 
law practice. It was developed based on bibliographic research and daily observation locating the subject in the Constitutional Law area.

\section{Key-words:}

Judiciary; Amendment, Reform, Slowness, Effectiveness, Swift.

\section{INTRODUÇÃO}

Por mais justa e correta que se apresente, uma sentença judicial pode, muitas vezes, ser ineficaz. Isso se verifica, em regra, quando a decisão chega a destempo, ou seja, quando a prestação jurisdicional é entregue ao jurisdicionado em momento que não lhe mais interessa nem mesmo o reconhecimento e a declaração do direito vindicado. Em conseqüência, não resta dúvida de que, se a prestação jurisdicional não for entregue contemporaneamente aos anseios do usuário do sistema Judiciário, o próprio direito pode perecer, uma vez que seu reconhecimento intempestivo, na maioria das vezes, não mais interessa ao seu titular, por não estar apto a produzir os efeitos almejados e necessários.

Nas palavras de Cândido Rangel Dinamarco:

"Os males de corrosão e frustração que o decurso do tempo pode trazer à vida dos direitos constitui ameaça à efetividade da promessa de tutela jurisdicional, contida nas Constituições modernas - e ameaça tão grave e tão sentida, que em tempos atuais se vêm afirmando que tal garantia só se considera efetiva quando for tempestiva" ${ }^{3}$

Nesse contexto, a denominada "morosidade processual" é a resultante direta de inúmeros fatores de difícil superação, notadamente de ordem estrutural do próprio Poder Judiciário. 0 reduzido número de juízes e de servidores torna penosa a judicatura, cujo trabalho também é dificultado pelas parcas condições materiais e orga-

${ }^{3}$ DINAMARCO, Cândido Rangel. Fundamentos do processo civil moderno, 4.ed. São Paulo: Malheiros, 2001.t. 2, p. 894. 
nizacionais, mesmo porque a idealizada "Justiça Virtual" é ainda uma possibilidade quimérica. Outra vertente que também contribui para a morosidade processual é intrínseca ao próprio processo, ou seja, o conjunto de regras que permite que o trâmite do processo se arraste por tempo indefinido, dilatando sobremaneira o prazo da entrega da prestação jurisdicional.

Tais situações que, na prática, ocasionam a estagnação da justiça, embora sejam públicas e notórias na visão dos operadores do direito, não são claras aos olhos dos usuários do judiciário para quem a morosidade processual é inexplicável e, por parecer intransponível, é objeto do mais absoluto inconformismo. Aos litigantes, sobrevém a sensação de que o direito se dilui pelo caminho à espera da prestação jurisdicional, tornando a justiça evanescente e longínqua como a voz inatingível dos sonhos, com reflexos nocivos, inclusive de ordem psicológica. Dessa caótica situação, emerge a descrença e a desconfiança contra o Poder Judiciário, gerando a revolta e a desestabilização da sociedade.

Sendo certo que o processo é o instrumento da jurisdição e que a função social dele é a distribuição da justiça, não se pode deixar de reconhecer que nas circunstancias atuais do Poder Judiciário, a entrega da prestação jurisdicional em tempo oportuno, capaz de produzir os efeitos desejados e atender às expectativas do titular do direito, é meio de pacificação e harmonização da sociedade. Conseqüência lógica disso é que a prestação jurisdicional tempestiva acalma os ânimos, põe fim à demanda e, ainda que a decisão proferida seja desfavorável ao postulante, confere credibilidade ao Judiciário e promove a paz social na medida em que desestimula a proliferação de novos conflitos.

\section{O DIREITO À RAZOÁVEL DURAÇÃO DO PROCESSO}

No Brasil, antes mesmo da EC n. 45, a celeridade processual já era reconhecida como garantia constitucional das partes litigantes, 
em decorrência da interpretação e aplicação da regrà do devido processo legal. Com o advento da aludida Emenda, o que antes era princípio idealizador, passou a ser prerrogativa que ostenta rótulo de fundamentalidade, estando hoje, por força da Emenda Constitucional n. 45 , de 08.12 .2004 , inserida no catálogo do art. $5^{\circ}$ da Constituição Federal. $^{4}$

Por ter sido erigido à categoria de direito fundamental, o direito à razoável duração do processo, segundo a moderna diretriz da interpretação constitucional, passou a ser dotado de eficácia máxima e imediata, até porque, no que diz com os direitos fundamentais, a Lei Magna deixou de ser mero repositório de promessas, carta de intenções ou recomendações; ela conferiu direitos subjetivos ao cidadão e à coletividade, amparando-os juridicamente para se obter a efetividade dos mesmos, realizando em concreto a prescrição constitucional como decorrência lógica do "princípio da aplicabilidade imediata e da plena eficácia dos direitos fundamentais" "que está encartado no §

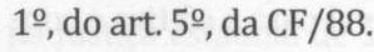

Ocorre que, apesar de se encontrar sob o signo da máxima efetividade, o direito fundamental da razoável duração do processo é, inegavelmente, um conceito indeterminado e aberto, vez que a redação do novel inciso inserido no texto constitucional não oferece uma resposta precisa de qual seria o tempo razoável de um processo.

Em função da omissão do legislador constitucional em estabelecer "o razoável prazo para a duração do processo", cabe a todos quantos atuam na seara processual, jurisdicional ou administrativa, atendendo à regra do princípio da proporcionalidade assegurar o respeito ao princípio constitucional ora em análise, até porque o direito processual moderno não se contenta simplesmente com a concessão do provimento jurisdicional, exigindo que este seja capaz de legitimamente proporcionar a tutela pleiteada, e isso o jurisdicio-

\footnotetext{
${ }^{4}$ LXXVII - A todos, no âmbito judicial e administrativo são assegurados a razoável duração do processo e os mei os que garantam a celeridade de sua tramitação.
} 
nado somente alcançará se a tutela for tempestiva.

Luiz Carlos Moro, a propósito de tal questão, alerta:

$\mathrm{Na}$ tentativa de contribuir para a mensuração temporal da garantia constitucional é que se tenta desenvolver o raciocínio condutor desse pequenino artigo, que insta os advogados a exigir do Judiciário a auto-imposição da razoabilidade prometida, sob pena de deixar o sentido da Constituição relegado à inobservância. E país que não respeita a sua Lei Maior não é país: é limite territorial da selvageria. ${ }^{5}$

\section{CAUSAS DA MOROSIDADE PROCESSUAL}

A morosidade é fato gerador de descrença no Poder Judiciário, estando a insatisfação presente em todos os setores sociais.

Afirma Marinoni que essa problemática tem especial gravidade, vez que estrangula os direitos fundamentais do cidadão, enfocando o processo como um instrumento indispensável para a efetiva e concreta atuação do direito de ação, bem como para a remoção de fatos impeditivos ao pleno desenvolvimento da pessoa humana e à participação de todos na organização econômica, política e social do país. ${ }^{6}$

De efeito, acentua que se o tempo gasto para a tutela de uma pretensão pode ser considerado uma necessidade, pode, outrossim, ser considerado uma imperfeição necessária do processo e que esta pode fazer com que o processo perca sua utilidade, ou deixe de atender os fins a que se destina. Esclarece, ainda, que, muitas vezes, o retardo na prestação jurisdicional pode transformá-la em mero adorno. ${ }^{7}$

A morosidade é, portanto, sintoma e foco de origem das crises que assolam o mundo jurídico. É um estado de coisas, uma caracte-

\footnotetext{
${ }^{5}$ MORO, Luiz Carlos. Como se pode definir a "razoável duração do processo". Disponível em <http://conjur.estadao.com.br/static/text/32536.1>.

${ }^{6}$ MARINONI, Luiz Guilherme. Novas linhas do processo civil. 3. ed. rev. e ampl. São Paulo: Malheiros, 1999, p. 33.

${ }^{7}$ Id., Tutela cautelar e tutela antecipatória. São Paulo: Revista dos Tribunais, 1992, p. 57.
} 
rística nem um pouco abonadora da prestação jurisdicional.

A lentidão é resultado de diversas causas, dentre as quais há que se destacar:

\subsection{CRESCIMENTO DA DEMANDA}

0 crescimento da demanda do judiciário brasileiro pode, sem hesitação, ser considerado uma das principais causas da morosidade judiciária. Concorreram para a procura da justiça em larga escala: o aumento da população, a evolução tecnológica, a ampliação do exercício da cidadania e ênfase sobre o direito das pessoas, através da Constituição Federal de 1988 e, também, a migração populacional do campo para a cidade, que se deu nos anos 80 , decorrente da industrialização do país. A par disso, o Brasil vem acompanhando um acúmulo explosivo de processos. Conforme pesquisa realizada pelo Conselho Nacional de Justiça em 2004 - "Justiça em números", a média é de três mil processos pendentes e novos casos por magistrado, na Justiça estadual de $1^{\circ}$ grau, no país. Oportuno observar, ainda, o expressivo número de ajuizamento de demandas inúteis a cargo do judiciário, eis que vários processos que tramitam na justiça poderiam ter resolução em outras instâncias administrativas. Inúmeros processos que tramitam na justiça brasileira poderiam ser resolvidos em menor tempo, com custo mais baixo, sem causar hipertrofia de atribuições judiciárias. Assim, com o excessivo ajuizamento de demandas, a análise e o julgamento das mesmas é impossível de ser realizada em tempo ideal.

\subsection{FALTA DE RECURSOS MATERIAIS}

A estrutura do Judiciário não se harmoniza com as novas exigências sociais, posto que não se aparelhou, nos últimos tempos, para o enfrentamento da demanda. Na grande maioria dos fóruns, há carência de materiais de consumo (computadores, impressoras, papel, etc.), bem como de condições apropriadas de trabalho. Em muitos lugares há juízes trabalhando em condições incompatíveis com a 
responsabilidade social da magistratura. A deficiência material vai desde as instalações físicas precárias até as obsoletas organizações dos feitos: $o$ arcaico papelório dos autos, os fichários datilografados ou até manuscritos, os inúmeros vaivens dos autos, numa infindável prática burocrática de acúmulo de documentos. Nesse panorama, detém-se como resultado a lentidão das atividades judiciárias. Matéria da Revista Consulex mostra que a atividade manual de consulta de processos, comparada ao atendimento com uso de computadores, dispõe de tempo consideravelmente superior. ${ }^{8}$ Considera Manzi que "não se pode admitir que fichas de processo amarelem em fichários e processos nos escaninhos quando a informática é cousa corriqueira até nos mais distantes grotões deste País." Sobre o tema, Mello declara, numa entrevista à revista Veja, que "em alguns lugares do Brasil, a justiça está num estágio pré-histórico, pois falta até papel e caneta. Se falta isso, imagine o resto."10

\subsection{CARÊNCIA DE RECURSOS HUMANOS}

O número de juízes, funcionários e auxiliares da justiça apresenta-se desproporcional ao fluxo de processos. A tal propósito, é de se enfatizar que há evidente descumprimento ao que dispõe o inc. VIII, do art. 93, da Carta Constitucional, ${ }^{11}$ cuja providência desponta como de singular importância, levando-se em conta que "no Brasil atual, a relação de 01 juiz para cada 25.000 mil habitantes, enquanto na Espanha é de cerca de 01 para 8.000 mil e na Alemanha

\footnotetext{
${ }^{8}$ Cf. ROURE, Denise de; PASSOS, Nicanor Sena. Reforma do Judiciário. Consulex, Brasília, DF, a. 1, n. 3, p. 19, mar. 1997. "Olhando-se 'fichinhas' para procurar um processo, num método manual, a consulta a um processo é feita em média em 30 minutos, enquanto $o$ atendimento completo em uma consulta em que o sistema está informatizado é de no máximo 5 minutos, sendo que no segundo o funcionário obtém os dados de três ou quatro processos no monitor de um computador". ${ }^{9}$ MANZI, José Ernesto. Da morosidade do Poder Judiciário e algumas possíveis soluções. Jus Navigandi, Teresina, a. 8, n. 337, 9 jun. 2004. Disponível em: http://jus2.uol.com.br/doutrina/texto. asp?id $=5312>$.

${ }^{10}$ SEM LEI NEM ORDEM. Revista Veja, São Paulo, a. 29, n. 50, p. 58, 11 dez. 1996.

${ }^{11}$ Art. 93, inc. XIII - 0 número de Juízes na unidade jurisdicional será proporcional à efetiva demanda judicial à respectiva população.
} 
de 01 para cerca de 4.000 mil". ${ }^{12}$ Neste contexto, há que se ponderar que a Emenda 45, por ora, vem surtindo um efeito inverso, conquanto ao extinguir as férias coletivas dos Juízes de $1^{\circ}$ e $2^{\circ}$ 을 Graus, sem atentar para existência de quantitativo suficiente de Magistrados, mormente no âmbito das Justiças Estaduais, para um funcionamento ininterrupto da atividade jurisdicional, ${ }^{13}$ acabou por emperrar ainda mais a máquina judiciária na medida em que, por força de lei, enquanto uns Juízes se vêem obrigados a gozar férias regulamentares, outros são sobrecarregados com as chamadas "substituições", automática ou por convocação, com evidente prejuízo à celeridade da prestação jurisdicional, tanto nos Juízos dos quais são titulares, quanto naqueles em que atuam em substituição.

\subsection{DESPREPARO DOS PROFISSIONAIS}

Há que se destacar, também, como fator grave, a falta de preparo, treinamento e reciclagem dos profissionais. Como causas desses fatores Svedas aponta os baixos salários e a sobrecarga de trabalho. ${ }^{14}$ Repare-se que, hoje, em qualquer empresa moderna, além do número adequado de profissionais com qualificação para o desenvolvimento do objetivo empresarial, há uma preocupação

\footnotetext{
${ }^{12}$ SILVA, José Afonso da, Comentário Contextual à Constituição, 3. ed. São Paulo: Malheiros, pg. 512.

${ }^{13}$ Art 93. inc. XII - A atividade jurisdicional será ininterrupta, sendo vedado férias coletivas nos Juizos e Tribunais de $2^{\circ} \mathrm{Grau}$, funcionando, nos dias em que não houver expediente forense normal, Juízes em plantão permanente.

${ }^{14}$ In SVEDAS, Andréia Mendes. Morosidade da justiça: causas e soluções. In: SZKLAROWSKY, Leon Fredja (Org.). Morosidade da justiça: causas e soluções. Brasília, DF: Consulex, 2001, p. 18. "O despreparo dos profissionais é um fator gravíssimo, permitindo a concretização da opinião pública ao ouvirmos que o Judiciário não funciona, e sim enrola 0 desinteresse dos profissionais se dá pelos seus baixos salários, a sobrecarga de trabalho é o reflexo da falta de previsão, juntamente com solução alternativa de que num determinado momento o Judiciário poderia sufocar-se pelo aumento de sua procura, a escassez de recursos é crucial, visto que a falta de ferramentas básicas impossibilita o melhor desempenho das funções, e a sobrecarga de trabalho é o resultado da morosidade".
} 
com o constante aperfeiçoamento, o que, seguramente, não deveria ocorrer de forma diversa no Poder Judiciário. A descrença na Justiça advém também da multiplicação de Faculdades e do déficit qualitativo, conquanto, o excesso de advogados é gerador de mais conflitos, e, são tênues os limites entre a advocacia e a esperteza.

\subsection{LEGISLAÇÃO INADEQUADA}

O descompasso se dá também em decorrência do número excessivo de leis. 0 excesso de leis acarreta dificuldade para saber quais delas vigem ou não, bem como se os comandos decorrentes se repetem ou são contraditórios. Na colocação de Manzi "as leis são muitas e muitas vezes mal feitas (principalmente as processuais, editadas sem a ouvida de especialistas)". ${ }^{15}$ Além do mais, não raras vezes, normas mal elaboradas geram interpretações incongruentes. As modificações parcimoniosas que estão sendo realizadas, ainda são insuficientes para a resolução da morosidade. Outro percalço é a deficiência da vontade política. Ao Legislativo compete a típica função de "elaborar as leis [...], mas cabe-lhe, outrossim, fiscalizar e impor a boa execução delas". ${ }^{16}$ No entanto, nossos legisladores, além de colaborarem com a lentidão, não respondendo de forma rápida aos anseios do país, por vezes, criam projetos de leis ineficazes, que resultam em leis inaplicáveis. Os exemplos são vários e seria tedioso enumerá-los. Basta lembrarmos do Código Civil Brasileiro, que permaneceu por mais de 30 anos, no entra e sai de modificações e só em dezembro de 1997 foi finalmente aprovado, com muitos preceitos já ultrapassados pela própria evolução social. 0 quadro caótico que se apresenta exibe a irresponsabili-

\footnotetext{
${ }^{15}$ MANZI, José Ernesto. Da morosidade do Poder Judiciário e algumas possíveis soluções. Jus Navigandi, Teresina, a. 8, n. 337, 9 jun. 20 04. Disponível em: http://jus2.uol.com.br/doutrina/texto. asp?id $=5312>$.

${ }^{16}$ MONTESQUIEU, Charles de Secondat, Barão de. 0 espírito das leis. Int., trad. e notas de Pedro Vieira Mota.3. ed. aum. São Paulo: Saraiva, 1994, p. 200.
} 
dade, o descaso, o despreparo e a omissão dos parlamentares. 0 Executivo, a seu turno, em vez de cumprir a legislação vigente ou desempenhar a função típica de executar, faz uso abusivo de medidas provisórias para formalizar assuntos jurídicos e satisfazer certas classes políticas e sociais. Destarte, decisões e liminares dessas medidas, com freqüência, são contestadas judicialmente, causando atritos com setores do Governo a abarrotamento de processos sobre assuntos repetitivos, que esperam pelo exame do Judiciário.

\subsection{FORMALISMO EXAGERADO}

0 formalismo tem por objetivo dar previsibilidade às decisões judiciais, contendo os arbítrios judiciais e equilibrando a relação entre as partes, mas acaba acarretando sérios problemas, como a protelação de um provimento. Muitos juízes, em absurda homenagem ao formalismo acabam por negar efetividade a um provimento jurisdicional célere. Na verdade, a burocracia, esse apego excessivo à forma, é a explicação para a exigência de documentos, guias, carimbos, autenticações, chancelas, protocolos, quando uma simples declaração bastaria para atingir o mesmo fim. À vista disso, registra Pedrosa: “Empecilhos de toda a ordem são impostos para a obtenção de documentos, obrigando os homens comuns a peregrinar pelas repartições, atônitos diante dos meandros burocráticos de idas e vindas de seus processos". ${ }^{17}$

\subsection{EXCESSIVO NÚMERO DE RECURSOS}

Outra barreira que contribui para a morosidade judiciária é o exagero de recursos. 0 número expressivo de recursos que, na maioria dos casos, são utilizados com finalidade protelatória, permite que um litigante percorra, em tese, pelo menos cinco instâncias jurisdi-

\footnotetext{
${ }^{17}$ PEDROSA, Valtércio. A lentidão do Judiciário brasileiro. Jus Navigandi, Teresina, a. 9, n. 749, 23 jul. 2005. Disponivel em: <http://jus2.uol.com.br/doutrina/texto.asp?id=7039>.
} 
cionais até o julgamento da questão, podendo esperar até dez anos para a conclusão do processo, fator que desestimula quem realmente precisa da justiça. Quanto ao número de recursos previstos no ordenamento, basta observar que nos termos do art. 496, do Código de Processo Civil, estão elencados oito tipos de diferentes recursos, sem contar a remessa de ofício, os embargos de declaração dobrados (a sentença e o acórdão), o agravo também dobrado (retido e de instrumento) e os recursos regimentais como os agravos regimentais, o que eleva este número para onze, afora o mandado de segurança que é freqüentemente manejado como sucedâneo recursal, com o que teríamos uma dúzia de recursos. 0 sistema recursal pátrio, não raras vezes, acaba por frustrar a efetividade do direito, compromete a instrumentalidade do processo e enseja críticas, uma vez que se constitui em um dos grandes fatores de eternização das demandas.

\subsection{PRIVILÉGIO DE PRAZOS PROCESSUAIS E RECURSO "EX OFFICIO"}

Um outro fato causador da morosidade jurisdicional reside na regalia dos prazos especiais concedidos ao Poder Público, como também o do recurso de ofício. Questões estas polêmicas, já foram objeto de vários pronunciamentos no STF. Alguns juristas vêem nos prazos privilegiados que são concedidos às entidades públicas, bem como nos recursos necessários, uma violação do princípio da igualdade de tratamento que deve ser dada às partes no processo ${ }^{18}$. Arruda Alvim também se manifesta taxativamente contrário à permanência ou manutenção de tais privilégios. ${ }^{19}$ Outros acreditam que tais pri-

\footnotetext{
${ }^{18}$ SILVA, José Afonso da. Comentário Contextual à Constituição, 3.ed. São Paulo, Malheiros, 2007, pg. 76. Observa "Quando a lei cria situações de desigualdade em confronto concreto com outras que sejam iguais, como o dispositivo que trata de forma desigual a entes que devam litigar em igualdade de condições'.

${ }^{19}$ ALVIM, J. E. Carreira. Alternativas para uma maior eficácia da prestação jurisdicional. Revista de Processo, São Paulo, v. 21, n. 84, out./dez. 2005, p. 181. Registra: "se os entes públicos, pela complexidade de sua estrutura, dependiam, ao tempo da promulgação do Código de Processo Civil de 1973, de prazo mais dilatado para sua defesa, tal já não se justifica numa Administração
} 
vilégios são plenamente justificáveis. Tais vantagens, no entanto, mostram-se incompatíveis com a realidade social, são atentatórias à igualdade processual e maléficas à prestação da tutela jurisdicional.

Superado o exame das causas geradoras da morosidade processual podem, sinteticamente, ser apresentadas algumas idéias que, dentre outras, muito podem contribuir para revolucionar o conceito de prestação jurisdicional: a) a racionalização da prática forense, com a eliminação de expedientes inúteis e a simplificação de atos, bem como das rotinas cartorárias; b) a adoção de técnicas gerenciais, enfocando motivação, treinamento, qualificação, uso de práticas aplicadas com sucesso em outras organizações, bem-estar de servidores e satisfação do jurisdicionado; c) o estímulo constante à utilização de tecnologias de informação, na busca incessante pela efetividade processual e comodidade do usuário da justiça; d) o emprego de diversos mecanismos (enxugamento da legislação processual, reforma do sistema recursal, mudanças de prazos, etc.) para uma melhora na prestação do serviço forense.

\section{EMENDA CONSTITUCIONAL 45/2004 - REENGENHA- RIA DA PRESTAÇÃO JURISDICIONAL}

A Reforma concretizada por via da EC n. 45/2004, sintetiza um verdadeiro esforço de reengenharia, perseguindo, por força da introdução de novas estruturas e rearranjos no campo da atribuição de competências, assegurar ao Judiciário maior agilidade no desempenho de sua tarefa básica, qual seja, a prestação jurisdicional, e, concomitantemente, oferecer-lhe o instrumental apto a resgatar a idéia de lisura, da celeridade e da desejada densidade quanto à segurança jurídica que deve impregnar seus pronunciamentos.

automatizada, com quadro de procuradores bem aparelhado, em melhores condições do que a parte contrária de agir em juízo". 
Perquirindo o universo da referida reforma constitucional, no tocante ao desiderato de se alcançar a célere entrega da prestação jurisdicional, o legislador inseriu no texto da reforma as seguintes regras: a) disciplinou a aferição do merecimento dos Juizes conforme o desempenho, pelos critérios objetivos de produtividade e presteza no exercício da jurisdição e pela freqüência e aproveitamento em cursos oficiais ou reconhecidos de aperfeiçoamento; b) impediu a promoção de Juiz que, injustificadamente retiver autos em seu poder além do prazo legal, não podendo devolvê-los ao Cartório sem o devido despacho ou decisão; c) estabeleceu a ininterruptividade da atividade jurisdicional, vendado férias coletivas nos Juízos e Tribunais de $2^{\circ}$ Grau, estipulando plantão permanente; d) preconizou que o número de Juízes na unidade jurisdicional deve ser proporcional à efetiva demanda judicial e à respectiva população; e) viabilizou delegação à servidores para prática de atos de administração e atos de mero expediente, sem caráter decisório; f) determinou a distribuição imediata de processos em todos os Tribunais, Juízos e Ministério Público; g) expandiu o efeito vinculante nas ações diretas de inconstitucionalidade e nas ações declaratórias de constitucionalidade; $h$ ) fixou a necessidade de repercussão geral da questão para admissibilidade de recurso extraordinário; i) estabeleceu a necessidade de criação de justiça itinerante para os Tribunais Regionais Federais e do Trabalho, assim como, para os Tribunais Estaduais; j) facultou a regionalização das Câmaras dos Tribunais Regionais Federais do Trabalho e dos Tribunais Estaduais; l) criou os Conselhos Nacionais da Justiça e do Ministério Público; m) extinguiu os Tribunais de Alçadas. ${ }^{20}$

A despeito das inovações introduzidas pela tão festejada reforma constitucional, para se imprimir no contexto fático a celeridade processual devida, há ainda um longo caminho a ser percorrido até que tais comandos venham a ser efetivamente implementados, con-

${ }^{20}$ Vide arts. 93, 102, 103-A, 103-B, § $4^{\circ}, 107, \S 2^{\circ}$ e $3^{\circ}, 111-\mathrm{A}, \S 2^{\circ}$, I, $112, \S 2^{\circ}$, II, $115, \S \S 1^{\circ}$ e $2^{\circ}$, 125, 130-A, da Constituição Federal, segundo redação dada pela EC 45/2004. 
quanto, a ausência de políticas públicas para corrigir as deficiências existentes e a própria a estrutura secular do Poder Judiciário, que ainda é refratária a muitas das inovações introduzidas, são fatores que somente deixarão de imperar com a gradativa mudança de certos paradigmas culturais da sociedade e a abolição de políticas retrógradas que ainda balizam a atuação da Administração Pública.

\section{CONSIDERAÇÕES FINAIS}

"Uma coisa é reconhecer e justificar os direitos do homem; outra coisa é garantir-lhes uma proteção efetiva" ${ }^{21}$

Assim como alhures, no Brasil falta incorporar à prática cotidiana muitos dos direitos e garantias fundamentais entalhados no texto da Carta Magna, dentre eles o preconizado no art. 5ㅜㅡ, inc. LXXVIII $^{22}$, malgrado a própria Constituição Federal disponha que "as normas definidoras dos direitos e garantias fundamentais têm aplicação imediata". ${ }^{23}$

Digno consignar que a morosidade subtrai a crença dos cidadãos na democracia. No entanto, a despeito da descrença, a democratização é um processo contínuo e permanente, que gradativamente vai se consolidando e, na medida em que isso acontece, novos caminhos vão surgindo em busca de soluções para a necessária celeridade processual.

Neste ponto, imprescindível se mostra a necessidade de haver uma convergência de vontades dos poderes Judiciário, Legislativo e Executivo para assimilar a complexa gama das inovações trazidas pela Emenda Constitucional n. 45/2004, cada qual assumindo a parcela de atribuições e competências que lhes é afeta para, as-

\footnotetext{
${ }^{21}$ BOBBIO, Norberto. A era dos direitos, trad. Carlos Nelson Coutinho, Rio de Janeiro: Campus, 1988.

${ }^{22}$ "A todos, no âmbito judicial e administrativo, são assegurados a razoável duração do processo e os meios que garantam a celeridade de sua tramitação".

${ }^{23}$ - Art. $5^{\circ}, \S 1$.
} 
sim, se alcançar a eficiência na prestação jurisdicional, princípio a que esta subordinada toda Administração Pública. ${ }^{24}$

Impende destacar que, no âmbito do Poder Judiciário, com a colaboração do Conselho Nacional da Justiça, vêm sendo implementadas políticas tendentes a minimizar as agruras atávicas que regem a atividade jurisdicional. A tal propósito, pode-se mencionar a abolição do nepotismo nos Tribunais, a fixação de normas com critérios objetivos para promoção ou remoção de Juízes, a uniformização de procedimentos disciplinares contra Magistrados, a padronização de várias rotinas cartorárias, a criação do sistema PROJUDI - justiça virtual nos Juizados Especiais, disponibilização de equipamentos de informática para diversos Tribunais, criação de banco de dados a nível nacional de diversas áreas de atuação do Judiciário, entre outros.

Na seara do Poder Legislativo, entre outros progressos significativos, destacam-se as edições: a) da Lei n. 11.382/2006, que introduziu modificações no processo de execução; b) da Lei n. 11.417/2006, que regulamentou a edição de súmulas de efeito vinculante; c) da Lei n. 11.418/2006, que regulamentou a incidência da repercussão geral para admissibilidade de recurso extraordinário; d) da Lei n. 11.419/2006, que dispõe sobre a informatização do processo judicial; e) da Lei n. 11.441/2007, que desjurisdicionalizou os processos de separações, divórcios e inventários.

O Poder Executivo, por ora, está a se mostrar reticente em dotar o Judiciário de meios adequados para que este possa exercer, com eficiência e eficácia, o mister que lhe incumbe com exclusividade, por força da ordem Constitucional. Falta-lhe, talvez, a sensibilidade necessária para reconhecer que a morosidade judiciária produz um retardamento no desenvolvimento nacional, influi negativamente na ordem econômica, desestimula investimentos, e, por conseqüência, abala a credibilidade da própria nação.

De tudo resulta a necessidade premente da construção de um

${ }^{24}$ Vide art. 39, "caput", da Constituição Federal. 
planejamento estratégico para o Poder Judiciário, mediante redesenho da governança que, por sua vez, deverá assumir compromisso com razões éticas ou de humanidade - apesar dos mais diversificados desafios a serem enfrentados por seus dirigentes - mas, que serão recompensados pelas vantagens da eficiência da prestação jurisdicional, colhendo a satisfação do cidadão, obtendo, em contrapartida a melhoria da imagem e da credibilidade pública.

Faz-se mister, nesse refletir, sair do planejamento e partir para a ação, contando, pois, com o engajamento de todos para que, finalmente, seja possível superar o estágio da retórica jurídica e dar vida à lição doutrinária sobre a instrumentalidade e efetividade do processo. Imperioso e justo afiançar, ainda, que um modelo ideal de justiça passa, necessariamente, pela racionalidade, celeridade e efetividade.

Por último, oportuno trazer a baila a seguinte questão: 0 que se espera do judiciário brasileiro? De um lado, emerge que a própria sociedade não sabe qual modelo de judiciário ideal. Se é a figura de um espectador inerte, de mãos atadas, ela considera a justiça descartável. Se atua como Órgão de transformação, ela o acusa de politização. A solução para tal impasse exsurge da prudência aristotélica: virtude prática de conscientizar-se e de agir em conseqüência com a ordem trágica. Em um mundo sem referências axiológicas unânimes, nem definitivas, o senso comum ou prudência humana constitui a virtude mais audaciosa e delicada. É preciso imergir no contexto social. É urgente repensar filosoficamente a instituição, questionando-a em tempo integral. Afinal, prevalece a indagação milenar formulada por Aristóteles: Boas leis ou bons juízes?

\section{REFERÊNCIAS BIBLIOGRÁFICAS}

ALVIM, J. E. Carreira. Alternativas para uma maior eficácia da prestação jurisdicional. Revista de Processo, São Paulo, v. 21, n. 84, out./ dez. 2005. 
BOBBIO, Norberto. A era dos direitos, trad. Carlos Nelson Coutinho, Rio de Janeiro: Campus, 1988.

BRASIL. Constituição federal, código civil, código de processo civil. Yussef Said Cahali (Org.). 5. ed. rev., atual. e ampl. São Paulo: Revista dos Tribunais, 2003.

DINAMARCO, Cândido Rangel. Fundamentos do processo civil moderno. 4. ed. São Paulo:Malheiros, 2001. t. 2.

MANZI, José Ernesto. Da morosidade do Poder Judiciário e algumas possíveis soluções. Jus Navigandi, Teresina, a. 8, n. 337, 9 jun. 2004. Disponível em: <http://jus2.uol.com.br/doutrina/texto. asp?id=5312 $>$.

MARINONI, Luiz Guilherme. Novas linhas de processo civil. 3. ed. rev. e ampl. São Paulo: Malheiros, 1999.

MARINONI, Luiz Guilherme. Tutela cautelar e tutela antecipatória. São Paulo: Revista dos Tribunais, 1992.

MONTESQUIEU, Charles de Secondat, Barão de. 0 espírito das leis. Int., trad. e notas de Pedro Vieira Mota. 3. ed. aum. São Paulo: Saraiva, 1994.

MORO, Luiz Carlos. Como se pode definir a "razoável duração do processo". Disponível em <http://conjur.estadao.com.br/static/ text/32536.1>.

PEDROSA, Valtércio. Alentidão do Judiciário brasileiro. Jus Navigandi, Teresina, a. 9, n. 749, 23 jul. 2005. Disponível em: <http://jus2.uol. com.br/doutrina/texto.asp?id=7039>.

ROURE, Denise de; PASSOS, Nicanor Sena. Reforma do Judiciário. Consulex, Brasília, DF, a. 1, n. 3, mar. 1997.

SEM LEI NEM ORDEM. Revista Veja, São Paulo, a. 29, n. 50, p. 58, 11 dez. 1996. 
SILVA, José Afonso da. Comentário contextual à constituição. 3. ed. São Paulo: Malheiros, 2007.

SZKLAROWSKY, Leon Fredja (Org.). Morosidade da justiça: causas e soluções. Brasília, DF: Consulex, 2001.

$\pm$ 